\title{
Political Participation of Disadvantaged Women in Decentralized Governance:A Shift from Social Exclusion to Political Inclusion (A Case Study of Dalit Women of 42 Mouza in Cuttack Sadar
Block of Odisha, India)
}

\author{
Dr Smita Nayak \\ Head \& Associate Professor, PG Department of Political Science, \\ Utkal University, Bhubaneswar, Odisha, India
}

Keywords: Disadvantaged, Dalit, Political Participation, Social Exclusion, Political Inclusion, PRIs, and Transformation

\section{Introduction}

For years together Dalit women in India have been subjugated to oppression and social exclusion. They have strived incessantly to liberate them from the womb of dogmatism and impoverishment. The founding father of our constitution Dr BR Ambedkar himself was from Dalit community. While spearheading the basic postulates of Indian Constitution as the Chairman of the Drafting Committee, Babasaheb Ambedkar incorporated judiciously the measures to ensure the upliftment of marginalised and impoverished sections of the society like the Dalits, Adivasis and women in particular. But as Nani Palkhivala epitomises the inner voice of the downtrodden classes in his epoch making book 'We the People' which dedicates itself to the "People, who gave unto themselves a constitution but not the ability to keep it; who inherited a resplendent heritage but not the wisdom to cherish it; who suffer and endure in patience without the perception of their potential". 1 This dictum aptly highlights the social exclusion dimensions characterising the oppression of the Dalit community especially the women.

As Sen2 argues "Social exclusion can indeed arise in a variety of ways, and it is important to recognize the versatility of the idea and its reach. However, there is also a need for caution in not using the term too indiscriminately (by skilfully using the language of social exclusion to describe every kind of deprivation whether or not relational features are important in its genesis). Indeed, the language of exclusion is so versatile and adaptable that there may be a temptation to dress up every deprivation as a case of social exclusion. There is, I fear, some evidence in the vast and rapidly growing literature on social exclusion that the language has run well ahead of the creative ideas involved. For reasons of intellectual clarity, there is a strong case for exercising conceptual discrimination, going beyond linguistic similarity. Sure enough, the exclusionary perspective can be very useful in some contexts, but it can also be linguistically invoked even when it adds little to what is already well understood without reference to relational features. Investigative usefulness is partly a matter of judgement, but it is important that critical scrutiny is exercised in deciding whether to invoke the powerful sometimes bewitching rhetoric of social exclusion. 
The socio-economic marginalised sections globally have gone through four phases based on inertia, restlessness, institutionalisation and self reliance. Sen indicates this in the sideline of his pioneering concept called 'relational exclusion "when he says "Relational exclusions may, in some cases, be brought about by a deliberate policy to exclude some people from some opportunities. The absence of direct aiming does not, of course, absolve the government involved from responsibility, since it has to consider what bad things are happening in the economy and how they can be prevented (and not merely the things that are directly "caused" by its own policies). Nevertheless, for causal analysis it may be important to distinguish between the active fostering of exclusion whether done by the government or by any other wilful agent and a passive development of an exclusion that may result from a set of circumstances without such volitional immediacy." 3

Among the factors responsible for evolving of India in to world's strongest republic, the triumph of most important facet can be attributed to the strengthening and empowerment of Panchayati Raj Institutions or PRIs. PRIs have ventured to voice for millions of timid and voiceless villagers across the nation. In the process, they have reciprocated with the needs of marginalised sections, especially the ST, SC and women. As one of the promising states in eastern India so far political awareness and activism is concerned, Odisha stands as an embodiment of tribal women's empowerment. In the politically active 42 Mouza Panchayat Samiti (Block), Dalit women leaders have not only joined PRIs in various capacities but have underscored the significance of education for igniting political consciousness. Keeping this as the backdrop the paper delves deep to explore core issues surrounding Dalit women leaders and their role in revamping the face of PRIs in Odisha.

\section{Objectives of the Study}

The study makes an introspective analysis of issues on empowerment of Dalit women like:

i. Socio-economic background of the Dalit women of 42 Mouza in Cuttack Sadar Block

ii. Level of information sharing among Dalit women on their rights, powers and duties.

iii. Changing role of Dalit women PRI leaders in political decision making last 20 years.

iv. Role of SHGs and NGOs in the process of emergence of Dalit women PRI leaders.

\section{Review of Literature}

There is a substantial volume of literature available on the core issue surrounding participation of women in PRIs and other peripheral issues and constraints related to leadership attributes. Some contemporary articles have been analysed to arrive at the hypotheses, a brief description of which has been given in the following paragraphs.

Ashok Kumar H, and HM Mohan Kumari (2014) 4 in their paper presents the structure and functions of Panchayat raj Institutions. It also highlights the social composition of elected members and their participation in the decision making process in PRIs. According to authors the inhibiting factors for effective women participation in Panchayat Raj Institutions (PRIs) are many and diverse. Such factors will help us to suggest practical ways to overcome some of the limitations in evoking women's participation.

Latha A. Pandit (2010) 5 considers that the political participation enables individuals to participate in the decision- making process and policy determination that affect their needs. Women's participation in the political process is important not only because it strengthens democracy but also helps them to represent their problems and negotiate a better deal. Though at the grass root level their number has increased after 1993, it is imperative to bring in not just a quantitative change but also a qualitative change in their participation.

Khanna Manuka (2009) 6 in his article on "Political Participation of Women in India" enumerates the factors which have resulted in a wide charm between the 'de jure' and 'defacto' status of political participation of women in India. According to author political participation is a complex phenomenon. For analysis of this complex phenomenon the author analysed seven factors and these seven factors, he grouped into three categories - Psychological variable, socio-economic variable and political variable. 
Ram Babu, AN Panda (2015)7 in their study considers that Panchayat Raj is not a new phenomenon in the country. Its mention in history goes back to more than 1000 years. Women's participation in mainstream political activity has important implications for the broader context of governance in any country. Reservation policy for women in the Panchayat can be an important instrumental measure for achieving improvement in their socio-economic status and empowering them. If reservations for women in Panchayat Raj Institution.

Aparajita Sarangi and Gitanjali Mishra (2013) 8 in their study undertake a re-examination of the relationship between the socio-economic status of women vis-à-vis political participation in tribal and non-tribal districts of Odisha. Besides, it also suggests suitable measures towards policy formulation for ensuring effective participation of women.

\subsection{Hypotheses}

Taking a cue from the review of literature the following hypotheses have been formed:

1. The membership of Scheduled Caste (Dalit) women in Panchayat Raj Institutions has positive impact in their access and control over information.

2. Because of SHGs and government's capacity building initiatives, the self confidence levels of Scheduled Caste women have been enhanced.

\section{Methodology}

Prominent Participatory methods have been adopted in the present study. The following aspects are considered important by the researcher:
a) Decentralization
b) Self determination
c) Sustainability
d) Leadership
e) Educational aspects.

The study attempts explorative analysis by dint of a mix of qualitative and quantitative methodology using tools like FGD, In-depth interview and survey methods. A sample of 60 Dalit leaders has been taken to arrive at the broad observations and conclusions.

\subsection{Sampling}

The universe for the researcher in this study concerns 42 Mouza in Cuttack Sadar Block of Odisha consisting of 21 politically active Panchayat. Out of this 5 important Panchayat comprising of 29 revenue villages have been included. So the sample size of 60 respondents consists of 15 Dalit Sarpanch contestants including the present incumbents, 15 contestants for the position of Panchayat Samiti Member and 30 contestants for the position of Ward Member Ward Member.

\subsection{Period of Study}

The Dalit women elected to PRIs belonging to 42 Mouza in Cuttack district of Odisha during the 2017 Odisha Panchayat Election held in three phases have been considered for the study.

\subsection{Area under Study}

42 Mouza belonging to the Sadar block of historic and former capital of Odisha, Cuttack district has been chosen as the area of study. Cuttack District9 is one of the oldest Districts of Odisha. It is an important city and District headquarters. Cuttack, which lends its name to the District, is known as the business capital of Odisha. The word Cuttack derives its name from the anglicized Sanskrit word Kataka, which has two meanings-one being military camp and the other being the seat of government, protected by the army. Literally, it also means the fort, referring to the ancient Barabati Fort, around which the city developed. This city takes pride in the fact that it had been the capital of Odisha, before its shifting to Bhubaneswar, the new capital. Geographically, it is 
located at a latitude of 20 degree 03 to 20 degree $40 \mathrm{~N}$ and a longitude of 84 degree 58 " to 86 degree $20 \mathrm{E}$. Cuttack city is flanked by Mahanadi river on the north and Kathajodi river on the south. Covering a geographical area of $3932 \mathrm{sq} \mathrm{kms,} \mathrm{the} \mathrm{District} \mathrm{is} \mathrm{highly} \mathrm{populated.}$

42 Mouza is a cluster of villages 10 situated on a river island in the Cuttack district, in the state of Odisha, India. The island is called 42 Mouza, meaning Group of 42 Villages. It has facilities like a high school, a college, a cold store which is the biggest in eastern India, and its own youth club. A small canal called 'Malia' (now, a stagnant water body) is the lifeline of the agrarian villages. Inhabitants of the village use the canal water for irrigation, pisciculture and bathing purposes.. Literacy rate of this village is nearly 74 percent.

\subsection{Collection of Data}

Keeping in view the objectives of the study the data is collected from primary and secondary sources. The primary data mainly consists of the following aspects:

Awareness and the attitude of the elected Dalit women representatives at various levels in PRIs under 42 Mouza belonging to Cuttack Sadar Panchayat Samiti and

Socio-economic and political empowerment level of Dalit women leaders of 42 Mouza.

Separate interview schedule was personally canvassed to sample elected Dalit women representatives at ZP, PS and GP levels to obtain their views and opinions.

The secondary data was collected from relevant books, magazines, periodicals, journals and official documents on PRIs including various reports of committees, and the Acts relating to PRIs in Odisha. Similarly, data was also collected from the office of Cuttack Zilla Parishad, Cuttack Sadar Panchayat Samiti, and selected Gram Panchayat like Bentakar, Arilo, Ayatpur, Barada and Bentakar having moral support for the Dalit contestants of PRIs under the block.

\section{Analysis of Data}

The collected data have been processed and analyzed both manually and with the help of a computer. Both primary and secondary data were tabulated to bring out systematic analysis of the impact of PRI membership on socio-economic and political empowerment of Dalit women. The data drawn from the various sources were analyzed and inferences drawn by applying statistical tools like averages, growth rate, percentages etc.

\subsection{Study findings}

Thorough analysis of questionnaires attempted to arrive at the following core findings that strengthen the veracity of the hypotheses drawn at the beginning of the study.

The study shows that while 38 out of 60 respondents have exemplified moderate knowledge about PRI activities, 19 members could reflect average knowledge. On the other hand 3 members seemingly had knowledge that can be bracketed under below average and no members in this regard have been placed under negligible knowledge category.

The most positive thing noticed in 42 Mouza belonging to Sadar Panchayat Samiti is an improvement in the awareness level of women in issues related to PRIs. As many as 84 per cent women have fair idea of the welfare programmes undertaken by the Panchayat in villages where the SHGs are working. Nearly 63 per cent were aware about the Panchayat meetings and equal number knew about the powers of PRIs.

The researcher could establish evidently visible link between growths of educational infrastructure with spread of awareness among Dalit women. The establishment of high schools and colleges have been accepted as the prime most reason for empowerment of Dalit women. It has been evident from the fact that out of 60 respondents, 12 are graduates, 14 are intermediates or $+2,31$ are Matriculates and 3 are LP and UP pass outs and no one has been found illiterate. 
Implementation of the policies and programmes laid down by the Govt. were regarded as the two core functions of Panchayat. 79 per cent of the respondents affirmed positively on the question regarding their awareness about the issues undertaken in their Panchayat. Most of these hover around the housing under Indira Awas Yojana, or construction work, pension schemes, maternity benefits etc.

Decision making is more and more coming within domain of Dalit women leadership. A larger chunk of women leaders are taking decisions instead of their husbands and other relatives. The demonstrated ability of women in Panchayat has brought about a change in Dalit women's image and the respect they receive from other as expressed by more than half the respondents. Around 76 per cent respondents expressed that people have started believing in the ability of Dalit women as Panchayat representatives.

Earlier Dalit women didn't show great interest in politics but by the time last Panchayat Election was held, their participation in the political process had raised the level of political understanding and empowerment. This indicates that the elected women members of the Panchayat are proud about their qualification and their emerging liberty with the political status, as representatives of the people, which has substantially elevated their social status both at home and outside.

\subsection{Limitations of the Study}

The study is restricted both by its geographical and intellectual scope. It's limited to only 42 Mouza, an area with some unique features of seclusion that cannot be further replicated in scattered or close knit areas. Similarly the communication on socio-economic aspects obtained from the respondents through questionnaire also may not be universal in nature, considering the geographic dichotomies and variance in political culture of the district. Also the Dalit coherence cannot be attributed to similar factors prevailing elsewhere in the district or Sadar block itself. This limits the study to a sizeable extent

\section{Conclusion}

In the conclusion, we can verify the veracity of the hypotheses and find it correct that membership of Dalit women in Panchayat Raj Institutions has positive impact in their access and control over information and because of SHGs and government's capacity building initiatives, the self confidence levels of Dalit women have been enhanced. So far as decision making is concerned, majority of them have been empowered to take decisions and understand the programmes and policies, which may be factored as a harbinger of democratic consciousness in such politically active coastal districts through PRIs.

\section{References}

[1] Palkhivala, Nani, https://www.google.co.in/search?q=nani+palkhivala,we+the+people\&rlz

[2] Sen, A, https://www.adb.org/sites/default/files/publication/29778/social-exclusion.pdf

[3] Sen, A, https://www.adb.org/sites/default/files/publication/29778/social-exclusion.pdf

[4] Ashok Kumar H., and H. M. Mohan Kumari, "Panchayat Raj Institutions and Rural Women in Mysore District, Karnataka", web source: shodhganga.inflibnet.ac.in

[5] Pandit, Latha A., "Political Leadership of Women: Constraints and Challenges", The Indian Journal of Political Science, Vol.LXXI, No.4, October-December, 2010, pp.1139-1147. ibid

[6] Khanna, Manuka (2009) "Political Participation of Women in India", The Indian Journal of Political Science, Vol.LXX, No.1, January-March 2009, pp.55-64.ibid

[7] Ram Babu and Panda, AN, "Women empowerment in Panchayati Raj System: Uttar Pradesh", International Journal of Applied Research, June 2015, Vol.1, No.8, pp.146-153. ibid

[8] Sarangi, Aparajita and Mishra, Gitanjali; "73rd Constitutional Amendment and Women's Empowerment an Empirical Study in Tribal and Non-Tribal Districts, Odisha”, Journal of Rural Development, October- December 2013, Vol. 32, No. (4) pp. 383-394. ibid

[9] Cuttack district portal, web source http://ordistricts.nic.in/district_profile/aboutus.php

[10] Profile 42 Mouza, web source :https://en.wikipedia.org/wiki downloaded 9 Nov'17 